\title{
Kujund kui narratiivi allikas iiri rahvajuttudes
}

\author{
Daíthí Ó hÓgáin
}

\begin{abstract}
Ar mo shlí isteach dom chun mo chuid oibre gach aon lá, gabhaim thar íomhá, bhreá de Shan Nioclás, seod ealaíne a bhronn Dochtúir Oscar Loorits na hEastóine orainn le linn dó a bheith in Éirinn sa mbliain 1952 - bronntas, go deimhin, atá ina shiombail agus ina íomhá ar an gcomhthuiscint agus ar an gcomhar idir scoláirí sa dá thír.
\end{abstract}

Igal hommikul Dublini Ülikooli kolledži iiri rahvaluule osakonda tööle minnes möödun ma 17. sajandi kunstniku loodud kaunist Püha Nikolaust kujutavast ikoonist, mille Oskar Loorits kinkis ülikoolile oma sundpaguluse ajal 1952. aastal tänutäheks Séamus Ó Duilearga juhitud iiri rahvaluule komisjonilt saadud abi eest väärtuslike eesti rahvaluulematerjalide säilitamisel. See pühapilt pole mõeldud üksnes ergutama meie vaimseid ja akadeemilisi püüdlusi, vaid kannab oma ehedas ilus ja salapäras ka väljakutset avardada inimfantaasiale avanevaid eredaid kujutluspilte. Seetõttu tundub mulle eriti sobilik kõnelda siinkohal kujundlikkusest traditsioonilises iiri rahvajutus ja avaldada seega tänu võimaluse eest üllitada käesolevas kogumikus oma kirjutis.

Tegu on mõistagi nii laialivalguva ja ulatusliku teemaga, et sellest saab rääkida igasuguse traditsiooni raames, olgu selleks siis rahvapärimus või loov kirjandus, kirjalik või suuline traditsioon. Rahva kujutelmade ja uskumuste põhitasandil ilmneb, et kujundile, mis sööbib indiviidi või grupi mällu, võidakse ümbritsevas kultuuris omistada mingi konkreetne tähendus. "Mis on kolm kõige pahaendelisemat asja maailmas?" on üks iseloomulikumaid pärimisi iiri folkloristikas, ja vastus sellele kõlab nii: "Valge hobune, maja mäekünkal ja ilus naine!"' Jättes hetkeks kõrvale praktilised kaalutlused nende kahtlustäratavate asjade puhul - kui nii vaid saaks! -, on siiski ilmne, et need kujutavad endast võimsaid kujundeid. See asjaolu on aidanud kahtlemata kaasa kõnealuse triaadi püsimajäämisele, ja me näeme, et paljud rahvausundi seisukohalt olulised asjad on samalaadselt kujundlikud - näiteks must kass, punasejuukseline naine, harakas rohelisel taustal, punane rebane, keda

http://haldjas.folklore.ee/tagused/nr24/iirijutt.pdf 


\section{Daíthí Ó hÓgáin}

kalamees merele minnes hallil kaldajoonel näeb, nirk, kelle kuju joonistub välja tõusva päikese taustal, jpt. Siinkohal tuleks veel lisada, et ennustuse olemus on teisejärguline. Mõnedele saab viidata kui rohkemal või vähemal määral hea- või pahaendelisele; see aga viib meid mõttele, et kujund on sageli põhikomponent ja kujundi tõlgendus vaid spekulatsioon, katse omistada sellele kujundi tähtsust ja paigutada see juba omandatud kogemuse või traditsiooni konteksti (vt ka Ó hÓgáin 1995).

Tugevatel kujunditel on oluline roll ka pärisnarratiivides. Seda just esteetilisuse osas, sest jutustaja püüab esituse õnnestumiseks saada kuulajaskonna oma mõju alla ja selleks peab ta oma kujutlusvõimet antud konteksti ja heade tavade piires maksimaalselt kasutama. Rahvusvahelise levikuga usundilise jutu End pühakuks pidav erak (The Self-Righteous Hermit - AT 756A) iiri versioonides esineb motiiv, kus mees kahetseb pattu ja valab nii kibedaid pisaraid, et nood lõikavad vett ja uuristavad jõesängi augud. See on hea näide universaalsest abstraktsete tunnete konkretiseerimisest rahvaluules ning loob jutustuses pingelise õhkkonna, kusjuures suuliste narratiivide tegelased väljendavad oma tundeid alati tegudes, mida omakorda tingib loo edasiandmisel toimuv väljendusprotsess.

Väga hästi illustreerivad seda kadunud Edinburghi teadlase Alan Brufordi hiliskeskaegsete kangelaslugude käsikirjade võrdlused samade tekstide suuliste versioonidega, mis tekkisid külades käsikirjade ettelugemise tagajärjel. A. Bruford räägib oma töös ka teadlikest kunstilistest võtetest, mida jutustaja lugu edasi andes kasutab.

On tõenäoline, et keskmine jutustaja, kes ei jäta kogu lugu sõna-sõnalt meelde, mäletab suurt osa sellest elavate piltide jadana, võib-olla isegi visualiseeritult, mida ta siis oma sõnadega kirjeldab; see võib olla koguni kõigi jutustajate loomulik lugude óppimise viis [---]. Tihti ilmneb, et jutustajal on stseen selgesti vaimusilma ees, eriti kui see on ebatavaline (Bruford 1969).

Võime ka lisada, et kujundid mängivad tihti põhirolli rahvajuttude tegelikul levikul, kõige selgemalt rändmuistendi puhul. Sellistes muistendites on palju üleloomulikku (vt ka Almquist 1991: 209-319), ${ }^{2}$ kuid need on alati seotud mõne nähtusega, mida inimesed tajuvad reaalsena. Näiteks mingi kääpa või haldja elupaigaga seotud muistend toob silme ette sellesarnase koha ja kellestki ajaloolisest isikust 


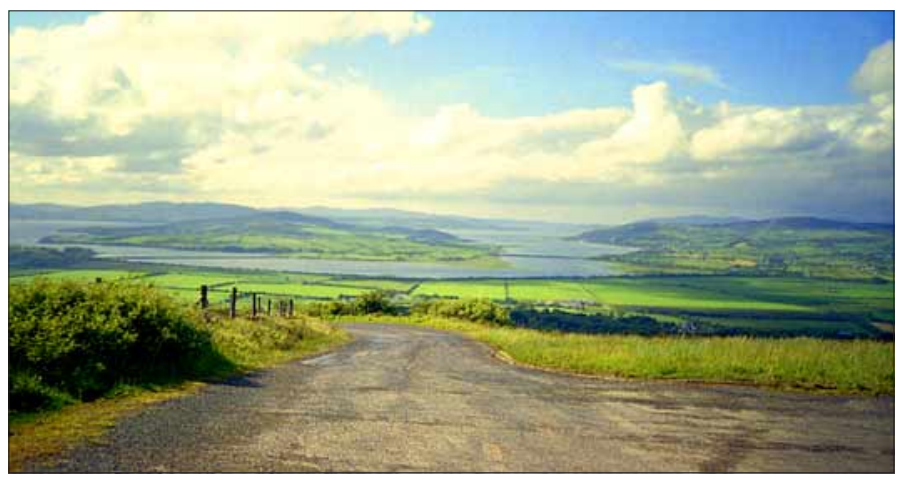

Foto 1. Tüüpiline Põhja-Iirimaa maastik. Foto Mare Kõiva 2003.

jutustav muistend mõne üldjoontes sarnaste tunnustega tegelase rahvapärimusest. Jutustaja teadvuses sobib seose loomiseks nii kujutlus kohast kui ka rahvapärimusest tuttav tegelane. See on näiteks ka põhjuseks, miks rahvaluules, mille traditsioonilised vormid eiravad ajaloolist kronoloogiat, üritatakse hoida lahus erinevaid jututsükleid ning samuti erinevaid ajaloolise pärimuse kogumeid. Jutustajate ja kuulajaskonna teadvust mõjutaksid justkui üldised taustteadmised ja nn etnoloogiline olevik (Schusky \& Culbert 1973: 110); see aga toetub kujunditele, mis on nii lähedalt seotud teatava pärimuskogumiga, et mis tahes muude pärimuskogumi sissetung antud konteksti muutub ebasoovitavaks või koguni vastuvõetamatuks.

Ülalpool sai juba mainitud, et kujundid on rahvausundis primaarsed ja tõlgendus sekundaarne. Seda saab pärimuse põhjal mitmel viisil illustreerida. Üks vanimaid ja püsivamaid kujundeid iiri pärimuses on kindlasti naine Iirimaa sümbolina (O'Rourke 19841985). See sümbol pärineb selgelt vanast keldi müüdist. MandriEuroopa ja Briti keltidel - nagu ka nende hõimlastel Iirimaal - oli tugev jõgesid ja maad kaitsvate emajumalannade kultus (Green 1995: 28-45, 89-116). Põhjalikumat arutlust selle pärimuse püsivusest Iirimaal (jumalannakultusest pühakukultuseni) ja ka kujundite tarvitusest võib lugeda Séamas Ó Catháini teosest The Festival of Brigit (Ó Catháin 1995). Emajumalanna kultus on pannud aluse tuntuimatele iiri pärimuslugudele, mis räägivad teispoolsusest pärit naisest ehk bean síst, keda kuuldakse nutmas sureva iirlase maja juures (Lysaght 1986). Tunnen paljusid, kes on teda nutmas kuulnud, 


\section{Daíthí Ó hÓgáin}

samuti kuuldakse teda tänini kõigis Iirimaa linnades. Väike analüüs aitab temas ära tunda kaitsva naisvaimu, kelle poolehoid surijale tuleneb iidsetest rituaalidest, milles keldi hõimupealikku käsitletakse maa kaitsehaldjana ja seega ka jumalanna müütilise kaaslasena (Byrne 1973: 15-17, 74-75; Ó hÓgáin 1999: 64-68, 165-168).

Teispoolsusest pärit naine pole seotud ainult iidsete kuningate ja pealike, vaid ka druiidide ja poeetidega, kes on alati ihaldanud otsustava tähtsusega rolli sotsiaalses sfääris. Üks vanem iiri tekst on selles suhtes võtnud üsnagi filosoofilise hoiaku, küsides luule kohta: Mis kujul see esineb? Ja vastus kõlab, et ta ilmutab end loomise hetkel ilusa neiu kujul (Gwynn 1940/42: 38). 17. sajandist alates on iiri poeedid käsitlenud seda kujundit pigem konventsionaalselt - nende luule üks lemmikteemasid oli kujutlus imelisest neiust, kes tõi neile sõnumi Iirimaa peatsest vabanemisest Inglise hirmuvalitsuse alt (Ó Buachalla 1996). Samas käsitleb hilisem rahvapärimus seda kujundit palju piiritletumalt ja jutupärasemalt, kirjeldades, kuidas rumal ja aeglase taibuga noormees heitis võlukünkale magama ja seal ilmutas end talle kaunis neid, kes talle luuleande kinkis (Ó hÓgáin 1982: 168-202). Niisiis kandus kujund filosoofiast kirjalikku traditsiooni ja sealt kindlasse narratiivi, kuigi vahest polegi tegu niivõrd edasikandumisega, vaid just traditsiooni kõikides arengustaadiumides olemasoleva arengupotentsiaaliga.

Iiri kirjandus on Euroopa vanim, kui mitte arvestada kreeka- ja ladinakeelset kirjandust, ja nõnda on iiri pärimuse uurijate kasutada ulatuslikud ajalugu ja geograafiat käsitlevad allikad. Pidades silmas, et antud kogumiku põhiteemaks on rahvaluule ja usund, üritan näidata, mis roll on tugevamatel kujunditel mütoloogilises tsüklis. Keskaegses kirjanduses sisaldab see tsükkel praegusaja teadmisi muistsest eelkristlikust iiri usundist, suundadest, mis olid nii tugevad, et avaldasid mõju ka seda jäädvustanud kloostriõpetlastele. Mõistagi lasid mungad-õpetlased mütoloogilisel tsüklil paista muinasjutulise muistse ajaloona, kuid nad olid ausad ja piisavalt avara silmaringiga, et anda tulevastele põlvedele mingisugunegi ettekujutus.

Alustagem väitest, mis pärineb mehelt, kes polnud kelt ega kristlane. See mees oli hoopis Julius Caesar ja ta tegi ülestähendusi suurima keldi rahva gallialaste kohta, kes asustasid lõviosa LääneEuroopast (gallialaste aastaringist on kirjutanud Jean Louis Brunaux oma teoses The Celtic Gauls (Brunaux 1988: 45-46, 70)): 
Kõik gallialased väidavad, et nad on Dis Pateri järeltulijad, ja ütlevad, et nii õpetavad druiidid. Sel põhjusel arvavad ja määravad nad aega mitte päevade, vaid ööde järgi; sünnipäevi, kuu loomist ja aasta algust arvestavad nad nii, et enne tuleb öö, selle järel päev (Caesar 1971: 221-222).

Selline päevale eelnevate ööde järgi ajaarvamine oli tuntud ka teiste muistsete Euroopa rahvaste hulgas (Pettazzoni 1956: 213) ning peegeldub tänapäeva iiri keelekasutuses ja teistes keldi keeltes. ${ }^{3}$ On selge, et Caesari gallialased nägid seost ööpimeduse ja surnud esivanemate isanda vahel, kuid kuidas see tegelikult ajaarvamisega seotud oli, on küsitav. Päike kui päevavalguse tooja on mõistagi aja esmane määraja, ent gallialased arvestasid aega päikese puudumise järgi. Seda võib selgitada väitega, et aja tajumine, nagu ka mis tahes muud abstraktsed teadmised, on pärit esivanemate asustatud ilmast, sellest maailmast, kuhu päike igal õhtul loojub. On olemas kaalukas tõendusmaterjal selle kohta, et muistses Euroopas usuti, et kui päike vajub läände, siis läheb ta allmaailma surnutele seltsiks (Pettazzoni 1956: 471).

Vanadel kreeklastel oli analoogne ettekujutus. Näiteks kirjeldas Hesiodos oma Teogoonias Vahemere lääneosa kui sissekäiku allilma, kuhu olid vangistatud titaanid: rõske koht, kus on hiiglasliku maa otsad ning kus öö ja päev lähenevad teineteisele ja tervitavad teineteist, astudes üle kõrge pronksist läve (Hesiodos: 508-520, 731733, 741-750). Päikese loojumise koht ei seostunud ainult teispoolsuse sünguse, vaid ka selle paeluvusega. Homeros viitab Elüüsiumi väljadele maailma äärel ([---] maailma otsa / Õndsate väljule [---]), kuhu mõned lähevad pärast surma ja kus on meeldiv olla ning Seal Okeanose võim paneb kergelt hõljuma läänest / Zephyros-tuule, mis toob elanikele ergutust värsket (Homeros 1963: IV, 563-568). Sealt ka arvamus, et teispoolsuse imeline saar Elüüsium asus läänemaailmas (Rose 1957: 58-59).

Varaseim kreeka uskumus Vahemere lääneservas asuva väinakitsuse kohta kõneleb sellest, et taevast toetas Atlase-nimeline hiid (Homeros 1963: I, 52-54; Julius Gaius Hyginuse Fabulae 150 - vt Graves 1960: I, 143-145). Aja jooksul koorus siiski välja teistsugune selgitus, mille järgi Herakles ehitas Gibraltari ja Abila kaljud Atlandi ookeani värava sammasteks (nn Heraklese sambad). See rajas teed uskumusele, et päike loojus topograafilise hiigelvõlvi taha, ja sellegi üle, mis jääb võlvi taha, on palju spekuleeritud. Väidetavalt sai selle 


\section{Daíthí Ó hÓgáin}

koha lähedal Herakles võitu kolmepealisest või -kehalisest Geryoneusest ning röövis tema veisekarjad (Hesiodos: 287-294, 981-983; Pettazzoni 1956: 213; Graves 1960: II, 132-133, 140, 392). Geryoneuse eluase oli Erytheial ("punane saar") - seegi on läände loojuvast päikesest tuletatud nimi. Saare täpne asukoht on vaieldav. Mõnikord on teda samastatud Cádizi-nimelise soise paiga või selle lähedal asuva saarega, mis arvatakse olevat lahku löönud Lusitaania (nüüdne Portugal) kaldast, kuid kõige levinuma arvamuse kohaselt asub see ookeani rannikust kaugel läänes (Graves 1960: II, 132-135, 140-141).

Mõned nimetatud kreeka kirjanikest on väitnud, et varem kasutati väinakitsuse kohta ka nimetusi Kronose sambad ja Briareuse sambad. Samuti annavad nad teada, et Cádizi läänepoolsel neemel asus Kronosele pühendatud tempel (Graves 1960: II, 135), mida nad võisid järeldada ülevaadetest selle piirkonna megaliitide kohta (Mohen: 1990: 106, 126-127). Ka Skymnos Chioselt on väitnud, et sambad asusid Gallia läänepiiril (Skymnos: 188), mis tähendab kujutluse levikut keltide asustusalale. Need kujutlused jõudsid Briti keltideni, keda mõjutas tugevalt Gallia keltide kultuur. Plutarchos väidab oma Moralias Demetriose-nimelise rännumehe jutu põhjal, et Britannia asukad paigutasid surnuteriigi üksteisega külgnevatele väikestele saartele ja et ühel saarel on vangis Kronos, kelle und valvab Briareus, sest uni on Kronost kinnihoidvaks ahelaks, ja tal on kaasas palju jumalaid, kes on talle teenijaiks ja kaaslasiks (Plutarchos: 419, 941; vt ka Brown 1943: 339-341). Plutarchos laenas nimed Kronos ja Briareus küll kreeka allikatest (Hesiodose Teogoonias oli Kronos lüüasaanud titaanide pealik, kes oli koos Briareusega vangistatud maa-alusesse Tartarosesse (Grant 1962: 87-88, 99-106, 419; Graves 1960: II, 387), kuid samas on Plutarchose hämmastavalt konkreetse aruande taga ilmselgelt autentsed keldi allikad (tema kommentaar Hesiodose kohta Brown 1943; vt ka Müller-Lisowski 1948):

Ookeani rannikul, Britannia vastaskaldal elavad ühed kalurid; kord kuulevad kalurid, kuidas keegi hü̈̈ab neid ja seejärel koputatakse uksele. Nad tõusevad oma asemeilt ja leiavad kaldalt rikkaliku laadungiga võorrad paadid. Kalurid haaravad aerud ja on tunni aja pärast vastaskaldal, kuigi enda paatidega oleks see teekond kestnud poolteist päeva. Kohale jõudes ei näe nad kedagi, aga ikka kuulevad häält hü̈̈mas maaleastunute nimesid (Müller-Lisowski 1948: 149-150). 


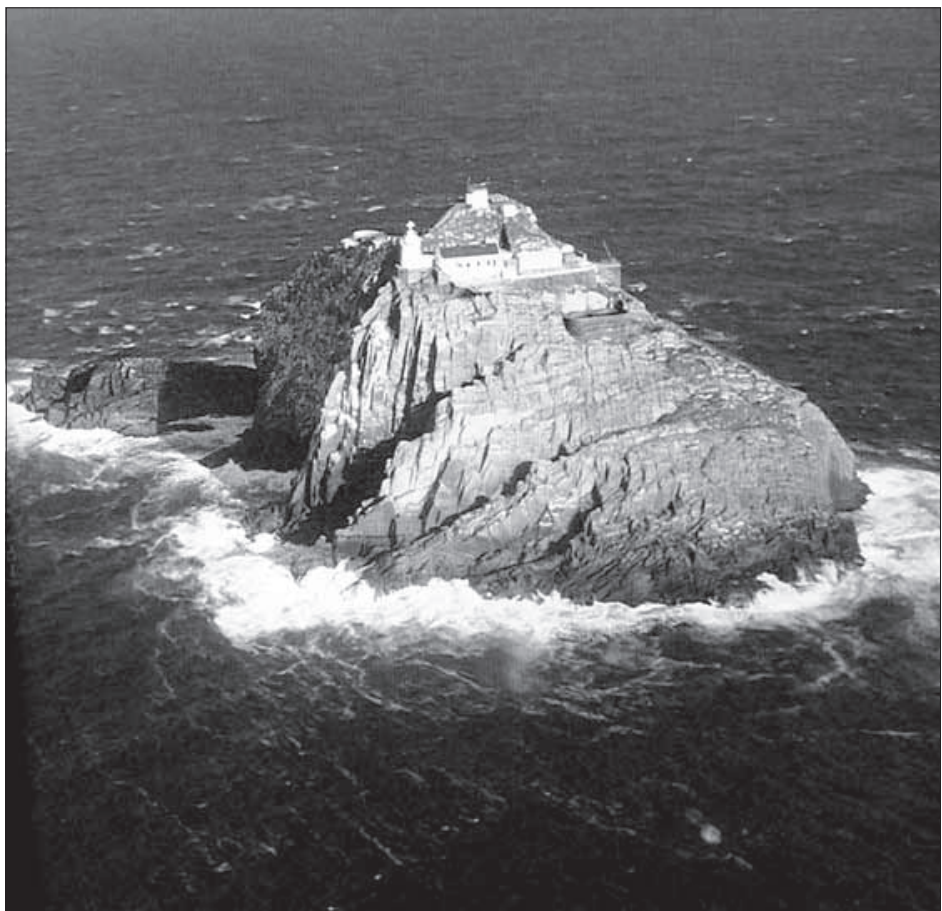

Foto 2. Teach Doinn (Bull Rock, Kerry maakonnas kalda lähedal), 'Donni maja' kuhu päike loojub. Dáithi Ó hÓgáini kogust.

Kuigi ka seda lugu on arvatavasti ilmestatud kreeka uskumusega hingede sõidutamisest üle Styxi jõe, tuleb rõhutada, et analoogne pärimus oli käibel Iirimaal surnute jumala ja tema maailma kohta (O’Rahilly 1946: 481-484). Selle jumala nimi oli Donn ehk "Tume" või "Must" (Walde \& Pokorny 1930: I, 846-847) ja teda kirjeldatakse kui Iirimaa edelaranniku lähedase kaljusaare asukat (MüllerLisowski 1948: 147-149). See Tech Duinni (Donni maja) nimeline lage ja tuuline kaljusaar on ebatavalise kujuga, moodustades loodusliku võlvi, mille alt meri tohutu jõuga läbi voolab.

Keskaegsed iiri tekstid räägivad paganate usust, mille kohaselt lähevad hinged Donni juurde (Gwynn 1924: 310-311; Macalister 1938-1956: V, 80-82, 106; Meyer \& Nutt 1895: I, 45-48; Meyer 1919: 542; Knott 1936: 9, 10, 22, 79), ja muistne luuletuses ${ }^{4}$ tsiteeritakse Donni sõnu: Cucum dom thig tíssaid uili íar bar n-écaib! (Minu juur- 


\section{Daíthí Ó hÓgáin}

de, minu majja tulete te kõik pärast surma!) (Todd 1848: 248; Best \& Bergin \& O’Brien 1954-1983: III, 520). Seda dolmenikujulist kaljut on väga loogiline seostada sissekäiguga surnuteriiki. Maismaal elavad inimesed märkavad ikka veel imelisi kiiri, mida päike õhtul läände loojudes üle kalju heidab. Siinkohal kerkib esile kontrast teispoolsuse hiilguse (millest on iiri allikates sageli juttu) ja surnuteilma ööpimeduse vahel.

Kujutlus, mis põhineb sellisel kontrastsel kujundil, on loomulikult vesi jutustajate veskile, ja siin tulevad mängu Axel Olriki poolt sõnastatud eepilised seadused: vastandite seadus ja lavalise kaksuse seadus (Dundes 1965: 129-141). Teisisõnu pani see elavate ja surnute maailma kahesus muistses keldi usundis aluse narratiividele jumalikest olevustest Fionnist (valge) ja Donnist (must) (Guénon 1962: 306-308). Näiteks on keskaegses Ulsteri tsükli pikimas ja vanimas proosaeeposes Táin Bó Cuailnge tegelasteks kaks härga, ühe nimi on Fionn ja teise nimi Donn, kes peavad omavahel ägedat võitlust (O'Rahilly 1976: 124, 237). Ühe jutustuse põhjal, mille järgi võitlesid nad omavahel varemgi, kuigi teiste olenditena, võib arvata, et tegu on vaid varasema pärimuse edasiarendusega (Roider 1979; Ó hÓgáin 1990: 167-168). Ja nii see oligi, kuni ajani kauges minevikus, mil

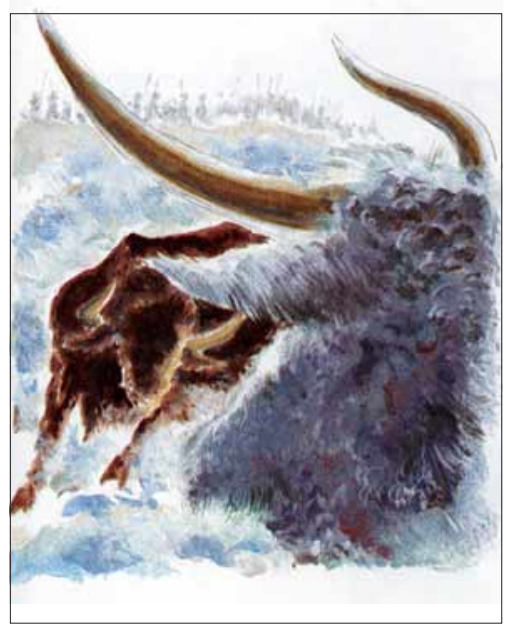

Foto 3. Donn ja Fionn, hele ja tume jõud härgade kujul, pilt lasteraamatust. Dáithí Ó hÓgáini kogust. nad olid elavate ja surnute suhet sümboliseerivad jumalused.

Kõige kuulsam tegelaskuju, muistse jumaliku nimega Fionn oli vana iiri legendi Fionn Mac Cumhaill kangelane. On tähenduslik, et ühes tuntuimas loos (vt Ní Shéaghdha 1967) on tema vastaseks sõdalane Diarmaid, kelle hüüdnimi on Donn (vt ka Breatnach 1968: 146-147; Ó hÓgáin 1990: 161-163). Ei üllata, et seda nime ja tegelaskuju kohtab ka keskaegses kõmri traditsioonis. Sealt loeme, kuidas kaks tegelast, Gwynn ja Gwythyr, on määratud teineteisega võitlema igal maipühal kuni maailma lõpuni (Gantz 1976: 168). Nimi Gwythyr (tuletatud ladina nimest Victor) (Brom- 
wich 1961: 403-404) on selgelt võorlaen; aga Gwynn on nime Fionn täpne kõmri vaste. Gwynni aga abistavad Annwfn'i (allilma) vaimud (Williams 1930: 99-101; Foster 1953: 446), mis käib aga Donni tegelaskuju kohta, ja nõnda ilmneb, et kõnealused kaks rolli on juhtumisi liitunud. Ühes teises keskaegses kõmri loos asendab Annwfn'i kuningat kangelane Pwyll, kes kannab hallikaspruune riideid ja peab võitlema iga-aastasel duellil Hafgani (suvevalge) nimelise tegelasega (Williams 1930: 2-6; Gantz 1976: 47-50). ${ }^{5}$

Uuemas folklooris jätkavad need kaks tegelaskuju oma perioodilisi jõukatsumisi. 20. sajandi keskpaigani räägiti iiri folklooris lugusid suurtest lahingutest kahe ebamaise väe vahel - lõunapoolse Munsteri haldjad Donn Fírinne juhtimisel ning läänepoolse Connachti haldjad Fionbharra juhtimise all. Jälle kohtame Donni ja Fionni ja võib oletada, et algselt võitsid nad kordamööda - Donn novembrilahingu ja Fionn mailahingu (Müller-Lisowski 1948: 156163, 195-196; Ó Danachair 1972: 121-124, 206-208). Värvikontrasti kujund oli aga niivõrd tähelepanuväärne, et jäi jutustajate lugudesse püsima. ${ }^{6}$

Pöördume tagasi Caesari ülestähenduse juurde, et varasema ajaarvamise järgi tuli öö enne päeva. Analoogselt toimus aastaringi arvestamine ka keltidel, kes paigutasid pimeda poolaasta heleda ette. Ó Shamhain go Bealtaine agus ó Bhealtaine go Samhain on selles kontekstis tavaline iiri lausung, mis tähendab: novembrist maini ja maist novembrini. Niisiis, nii päeva- kui ka aastatsükliga andsid keldid esivanematele elavate ees eesõiguse. Sedalaadi arusaama alusel läksid muistsed iirlased veelgi kaugemale ning kohandasid selle oma retoorika ja kuningate ametissepühitsemisega kaasnevate rituaalidega. Oma rituaalides kuulutasid nad, et jumalast esivanem on andnud maa valitsemise õiguse maisele kuningale (Ó hÓgáin 1990: 195-197; Ó hÓgáin 1999: 154-156, 173174).

Sellised püsivad traditsioonid moodustasid hea pinnase narratiivide tekkeks. Üks kõnekas näide sellest on keskaegne lugu kahest iiri mütoloogias tuntud tegelasest. Üks neist oli isa-jumalus, kes esines enamasti nime all Daghdha - see nimi pärineb keldi sõnast *dagodevos ja tähendab head taevajumalat, mistõttu kajastab ka teiste indoeuroopa keelte taevajumalate nimede tähendusi. Teiseks tegelaseks oli tema poeg Aonghus (kelle nimi tähendab tõelist elujõudu), kuid kes on tuntud ka nime all Macán Óg (noormees), mis on samastatav noore keldi jumala Maponose 


\section{Daíthí Ó hÓgáin}

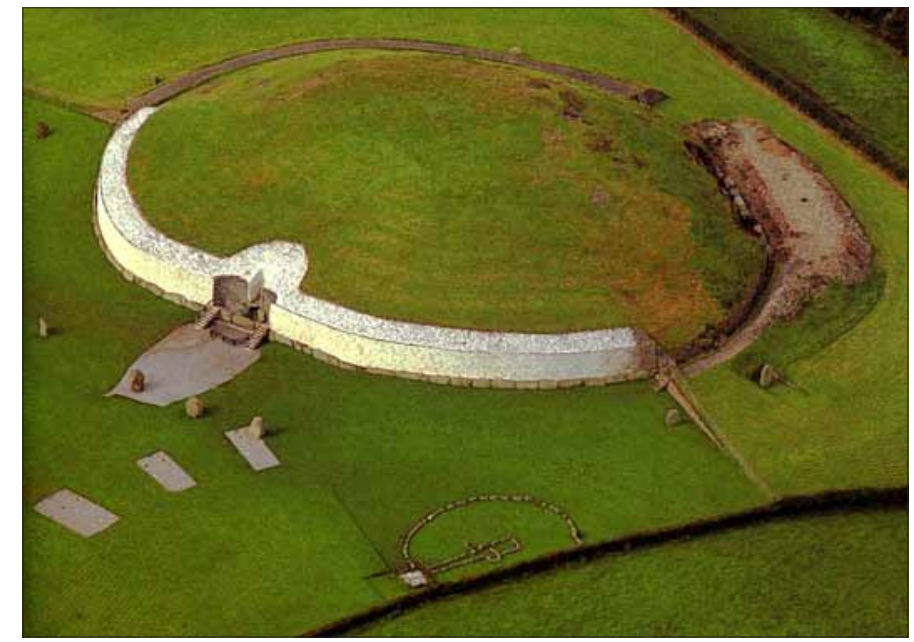

Foto 4. Brugh na Bóinne (Newgrange, Meath maakond), eelajalooline kalme. Foto Dáithí Ó hÓgáini kogust.

nimega nii Briti saarte kui ka mandri traditsioonis (O'Rahilly 1946: 516-517; de Vries 1961: 76-77; Green 1992: 140). Selle loo järgi oli Iirimaa suurim eelajalooline kääbas Brugh na Bóinne Daghdha asupaik, aga Aonghus küsis talt seda laenuks ööks ja päevaks (for a night and a day). Kui Daghdha talt oma elupaika tagasi küsis, keeldus Aonghus seda andmast, vastates, et ööde ja päevadega saab maailm ära kasutatud (it is nights and days that the world is spent) (Hull 1931: 53-58; Gwynn 1906: II, 18-21; Duncan 1932: 188-192; Bergin \& Best 1938: 142-147, 227; Ó hÓgáin 1999: 109-113). Niisiis, vana keldi mütoloogia ja rituaalide riismed andsid keskaegsetele jutustajatele põhjuse luua uus narratiiv, mis tugineb tegelastevahelisele kontrastile. Et see toimiks, laenati folkloorist sõnamängu sisaldav rändmotiiv. ${ }^{7}$

Selle loo üldine meeleolu võib tunduda liiga humoorikas, isegi farsilik ja seetõttu sobimatu vanadele auväärsetele jumalatele. Me võime ju nentida, et nii läks siis muistsete jumalatega, ent püsima jäi teisi pärimusi, kus nad olid endiselt au sees. Keskse tähendusega iiri mütoloogilises tsüklis on Cath Mhuighe Tuireadh, jutustus suurest ürglahingust, kus kaht, jumalikku või pooljumalikku päritolu olendid on seatud vastakuti. Heatahtlikumasse rühma kuulujad kannavad nime Tuatha Dé Danann (otsetõlkes jumalanna Danu hõim) 
- nimi, millel on seoseid iidse keldi jumalate triaadi Teutatese (Marcus Annaeus Lucanuse Pharsalia; vt Green 1992: 208-209) ${ }^{8}$ ja Euroopa jõejumalannaga *Danuv- (vt Walde \& Pokorny 1930: I, 1224-1238; Jackson 1953: 379; Rees \& Rees 1973: 52-53, 364-365; Mallory \& Adams 1997: 486-487; Ó hÓgáin 1999: 64-68, 227). Vastased, kes kandsid nime Fomhoire, pidid samuti olema mütoloogilist päritolu, sest nende nimi tähendas allilma vaime (Contributions 1913-1975: fomóir; Gray 1982: 132) ja viitas jumaluste sfääri pahatahtlikumale küljele. Üks allikas nimetab neid "sídh'i tugevateks meesteks" (Gray 1982: 34) ja kujutelm neist võib olla välja kasvanud süngest ja pimedast kalmudemaailmast, mida järelikult peeti kirka teispoolsuse vastandiks, seda täiendavaks vastandiks. Tuatha Dé ja Fomhoire ei olnud tõepoolest täiesti eraldiasetsevad rühmad, sest mitmeid müütilisi ja kirjanduslikke kangelasi omistatakse kord ühele, kord teisele kogukonnale (O'Rahilly 1946: 483; Gray 1982: 134-135; O’Brien 1962: 117).

Nagu Donni-Fionni kooslus, väljendub ka kontrast Tuatha Dé ja Fomhoire vahel just ägedas võitluses. Siit leiame paralleeli jumaluste ürgse võitlusega teistes kultuurides ${ }^{9}$ ja taas tundub, et sellelaadne süžee on laenatud vastasseisu dramatiseerimiseks. Varasemates versioonides algas võitlus merel ja seda peeti meresammas tuiri pärast (Macalister 1938-1956: II, 249 ja III, 122-125, 128-131, 138-145; van Hamel 1932: 21-22). ${ }^{10}$ Sammast on kirjeldatud kui hiiglaslikku kuld-, hõbe- või kristalltorni, mis oli iiri traditsioonis tüüpiline päikesesümbol. ${ }^{11}$ Siitki kumab läbi pimeduse ja valguse ürgse vaheldumise kujund, mis väljendub loojuva päikese sisenemises surnuteriiki läänepoolses meres. ${ }^{12}$

Loos, mille on jäädvustanud keskaegsed kirjutajad, leiab võimas ürglahing aset siiski mitte meretornis, vaid sisemaal, ja seesugune arendus tuleneb otseselt kõnealusest kujundist. LoodeIirimaal Sligo maakonnas asub geoloogiliselt silmatorkav pinnavorm, mis koosneb mitme hektari ulatuses sadadest püstistest kividest, seepärast on see koht saanud nimeks Magh Tuireadh ("sammaste väljak"). Siia paigutasidki keskaegsed müütide kirjapanijad müüdi tegevuse - ilmselt seetõttu, et nende arusaamise järgi ei olnud meri kahe suure armee lahinguks loogiline paik. Müüdi kirjapanijate kujutluses muutus esmaseks just samba või sammaste juures peetud võitluse kujund. Eepose koostamisele aitasid kaasa ka teised kujundid ja siinkohal oleks sobilik tuua ära lühike sisukokkuvõte. 


\section{Daíthí Ó hÓgáin}

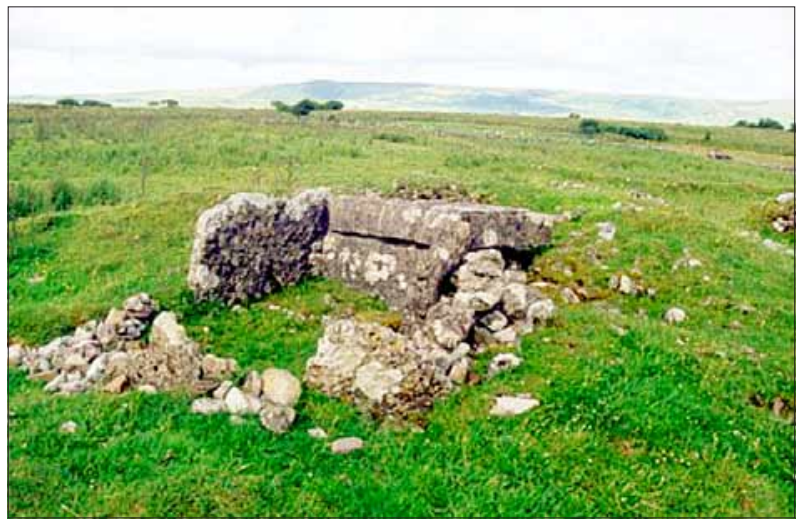

Foto 5. Magh Tuireadh, eelajaloolised märgid Sligo maakonna ‘kaljutasandikul’. Foto Dáithí Ó hÓgáini kogust.

Tuatha Dé moodustas Fomhoirega liidu ja selle kinnituseks abiellus üks Tuatha Dé meestest Fomhoire kuninga Balari tütrega. Sellest liidust sündis imelaps Lugh. Aja jooksul hakkas Fomhoire Tuatha Déd ägedalt rõhuma ning viimane ei näinud muud valikut kui vastu panna. Tuatha Dé valmistus suureks lahinguks, sepp Goibhniu sepistas võimsad relvad ja arst Dian Chécht varus rohtusid. Ent nende kuningas Nuadhu oli eelmises lahingus haavata saanud ja kuna vigastus muutis ta teovõimetuks, oli Tuatha Dé hõim nõutu. Lahingu eelõhtul saabus nende leeri keegi nägus võorras, kes näitas, et ta on meister igas töös. See oli Lugh, kes valiti järgmisel päeval lahingut juhtima. Fomhoire pealik oli tema emapoolne vanaisa Balar, kelle leegitsev silm hävitas kõik, mida ta vaatas.

Niipea kui lahing algas, põgenes Lugh oma väe juurest ja piiras vaenlase ümber, liikudes ühel jalal, üks silm suletud, ja laulis loitsu vaenlase vastu. Sellest sai kohutav veresaun, mille käigus hukkus ka Nuadhu. Siis seisis Lugh silmitsi Balariga. Kate liikus Balari silmilt nonda, et ta saaks heita pilgu Tuatha Déle ja sellega kogu hõim hävitada, ent Lugh heitis tema pihta lingukivi ning pööras ta silma kukla taha nii, et see pöördus Fomhoire vastu. Balar langes surnuna maha, ja suur osa Fomhoire armeest hukkus ta silma hävitava mõju läbi. Tuatha Dé mitmekordistas oma jõude ja Fomhoire oli täielikult kukutatud. 
Daghdha (isa-jumalus) ja Mor-Rioghain ("Suur Kuninganna", maajumalanna lisanimi) kohtusid ja ühinesid lahingu ettevalmistamiseks. Nü̈̈d sai Daghdha tagasi kogu Iirimaa veisekarja, mille Fomhoire oli ära võtnud, ning Mor-Ríoghain pidas suure võidu puhul kõne. ${ }^{13}$

On selge, et jumal-isa ja maajumalanna roll on liikunud loo tagaplaanile tänu lahingu seisukohast palju kõnekamatele leegitseva silmaga Balari ja mitmekülgse Lughi kujunditele. Lugh on tegelikult jumal Luguse iiri vaste; Luguse kui saagikuse ja kaubanduse patrooni kultus oli vanade keltide maailmas laialt levinud ja tema nimi kajastub paljude paikade nimedes, mida muiste nimetati tema kindlusteks (Lugudunum), näiteks Lyon, Laon ja Leiden (Holder 1896: II, 308-346; Ó hÓgáin 1990: 272-277). Võib oletada, et Balari kujund on tuletatud päikese destruktiivsest mõjust. Siinkohal saame aga olla tunnistajaks huvitavale nähtusele, mida võiks nimetada kahestunud isiksuseks. Võitlus vastab kindlasti mõnes mõttes traditsioonilisele pimeduse ja valguse vastandamisele, kuid Balari isiksuses on need mõlemad jooned olemas ning on ühendatud üsna seosetul viisil. ${ }^{14}$ Tema heitlus Lughiga pärineb tegelikult hoopis teisest süžeeliinist, mis jõudis keltideni Lähis-Idast Kreeka vahendajate kaudu - nimelt ettekuulutus lapsest, kes tapab oma türannist vanaisa. ${ }^{15} \mathrm{Ka}$ tuleb märkida, et kirjutajad on mingil määral lasknud oma lahingujutustust mõjutada Piibli lahingukirjeldustel, eriti just Taaveti võitlusel Koljati vastu (1. Saamueli raamat, 17. ptk). Hilisema allika järgi saab Lugh oma relvaks lingukivi, kuigi samas on palju tõendusmaterjali selle kohta, et algselt oli tema relvaks võimas oda (O’Rahilly 1946: 58-74). ${ }^{16}$

Kogu see tegelaskujude ja jutustuse süžeede tobuvabohu on jätnud varju loo muistse allika ja seetõttu on loo edasiandjad teinud nii, nagu head jutustajad ikka - püüdnud loole anda oma jutustuses sisu, keskendudes tegelaskujudega seotud tugevatele kujunditele. Siitpeale huvitas jutustajaid ja kuulajaskonda Balari leegitsev silm, Lughi oskus relva käsitseda, isa-jumaluse ja ema-jumaluse soojätkamisülesande täitmine ning kummaline, kuid reaalne koht maastikul, kus lahing olla peetud.

Jutt on iiri folklooris jäänud tänapäevani püsima ja on huvitav jälgida, kuidas keskaegset kirjalikku versiooni on alates 19. sajandist suulistes teisendites kohendatud ja ümber tehtud (Ó hÓgáin 1990: 276-277). Enamik tavalistest jumalikest tegelastest on jäänud 


\section{Daíthí Ó hÓgáin}

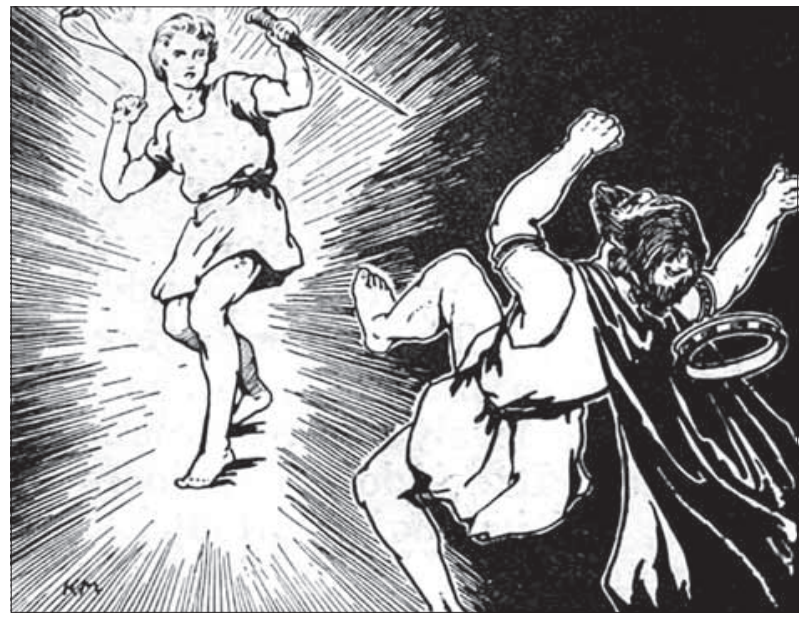

Foto 6. Lugh ja Balar, eepilise võitluse pilt vanast õpikust, Dáithí Ó hÓgáini kogust.

tagaplaanile, välja arvatud sepp-jumal Goibhniu, kes elab jutustuses edasi noore Lughi kaitsja ja abilisena. Lugh ise esineb vaid türannist vanaisa tapjana ja on ilmne, et just Balar ise - tänu leegitseva silma kujundile - on aidanud lool suulises pärimuses püsima jääda.

Tõlkinud Maarja Villandi

\section{Kommentaarid}

${ }^{1}$ Iiri keeles: "Cad iad na trí nithe is míámharaí amuigh?" - "Capall bán, tigh ar ard, agus bean bhreá!"

${ }^{2}$ Lisaks veel mitu kirjutist ajakirja Béaloideas köidetes 59-63 (19911995).

${ }^{3}$ Sõna öö (iiri oíche, kõmri nos) kasutatakse pühade eelōhtu märkimiseks.

${ }^{4}$ Luuletuse autor oli Fahani Máelmuru Donegali maakonnast (srn 887 $\mathrm{pKr}$ ).

${ }^{5}$ Need ja teised müüdikajastused iiri ja kõmri traditsioonis vt Alwyn Rees \& Brinley Rees Celtic Heritage (Rees \& Rees 1973: 283-286). 


\section{Daíthí Ó hÓgáin}

${ }^{6}$ Selles dualistlikus formuleeringus võivad peituda Fionni ja allilma sõdalase vahel Samhaini pidustuste ajal peetud võitluse juured - neid võitlusi on keskaegsetes iiri lugudes kirjeldatud mitmel viisil (vt Ó hÓgáin 1988: 9-10, 52-55, 92-93).

${ }^{7}$ Sõnamängu variantide kohta, nt homme ei tule kunagi (tomorrow never comes) jne, vt Ó hÓgáin 1992/93: 59-61.

${ }^{8}$ NB! Tuatha Dé Dananni kohta on ka nimetused trí dée Tuath, fir Trí nDéa (kolm hõimu jumalat, kolme jumala mehed või kolme jumalanna mehed) (Best \& Bergin \& O’Brien 1954-1983: I, 43; Gray 1982: 38).

$9 \mathrm{Nt}$ võitlused devade ja asurate vahel sanskriti kirjanduses, Aesiri ja Vaniri vahel muinasskandinaavia kirjanduses, Zeusi perekonna ja titaanide vahel vanakreeka kirjanduses.

${ }^{10}$ Samalaadsete teispoolsuse sammaste kohta vt van Hameli Immrama (van Hamel 1941: 42) ja John O'Meara The Voyage of Saint Brendan (O’Meara 1978: 68-69).

${ }^{11}$ Päikesemaja kohta iiri pärimuses vt Contributions 1913-1975: grianán; O’Rahilly 1946: 293.

12 See meenutab gallialaste püstitatud Jupiteri sambaid, mille tipus kujutatakse humanoidkoletisest jagu saavat ratsameest (Green 1986: 61-65; Green 1992: 127-128).

${ }^{13}$ Kogu tekst Gray 1982. Vt ka Murphy 1953/55: 191-198; Mac Cana 1980: 108-110.

14 Balar (<*Belerios) võib olla keldi päritolu nimi, mis omistati eelkeldi jumalusele pronksiajal (O’Rahilly 1946: 59-61; Ó hÓgáin 1990: 43-45; Ó hÓgáin 1999: 137-140).

15 Selle Sargoni, Moosese, Kürose ja Perseusega seotud süžeeliini kohta vt Rank 1914: 12-44; Krappe 1927: 1-43; Saintyves 1928: 229-272; Gruffydd 1928: 350-375. Teine versioon legendaarse Kreeka Edela-Hispaania kolooniast Tartessosest pärit kuninga Habise kohta on leidnud mainimist 2. sajandi pKr ladinakeelses kirjanduses (nt Justinus 44.4).

${ }^{16}$ Rahvalikes versioonides tapab Lugh Balari odaga, mille valmistas talle sepp Goibhninn (< Goibhniu).

\section{Kirjandus}

Almquist, Bo 1991. Crossing the Border. Béaloideas: Iris an Chumainn le Béaloideas Éireann = The Journal of the Folklore of Ireland Society 59, lk 209-319. 


\section{Daíthí Ó hÓgáin}

Bergin, Osborn Joseph \& Best, Richard Irvine 1938. Tochmarc Étaíne. Ériu 12, lk 137-196.

Best, Richard Irvine \& Bergin, Osborn \& O’Brien, Michael A. 1954-1983. The Book of Leinster, formerly Lebar na Núachongbála. Dublin: Dublin Institute for Advanced Studies.

Breatnach, Risteard A. 1968. Tóraigheacht Dhiarmada agus Ghráinne. Myles Dillon (toim). Irish Sagas. Cork: Mercier Press, lk 138-151.

Bromwich, Rachel (tõlk ja toim) 1961. Trioedd Ynys Prydein. Cardiff: University of Wales Press.

Brown, Arthur Charles Lewis 1943. The Origin of the Grail Legend. Cambridge: Harvard University Press.

Bruford, Alan 1969. Gaelic Folk-Tales and Medieval Romances: A study of the early modern Irish 'romantic tales' and their oral derivatives. Dublin: Folklore of Ireland Society.

Brunaux, Jean Louis 1988. The Celtic Gauls: Gods, rites and sanctuaries. London: Seaby Ltd.

Byrne, Francis John 1973. Irish Kings and High-Kings. London: Batsford.

Caesar, Gaius Julius 1971. Märkmeid Gallia sõjast (De Bello Gallico). Ain Kaalep \& Richard Kleis et al. (tõlk). Rooma kirjanduse antoloogia. Tallinn: Eesti Raamat, lk 219-222.

Contributions 1913-1975 = Contributions to a Dictionary of the Irish Language. Dublin: Royal Irish Academy.

Duncan, Lilian 1932. Altram Tige Dá Medar. Ériu 11, lk 184-225.

Dundes, Alan 1965. The Study of Folklore. Englewood Cliffs: Prentice Hall.

Foster, Idris L. 1953. Introduction. Gerald Murphy (koost). Duanaire Finn $=$ The book of the lays of Fionn 3. Dublin: Educational Co. of Ireland.

Gantz, Jeffrey (tõlk) 1976. The Mabinogion. Penguin: Harmondsworth.

Grant, Michael 1962. Myths of the Greeks and Romans. New York: Weidenfeld and Nicolson.

Graves, Robert 1960. The Greek Myths 1-2. Penguin: Pelican Books.

Gray, Elizabeth A. (toim) 1982. Cath Maige Tuired = The second battle of Mag Tuired. Naas: Irish Texts Society.

Green, Miranda Jane 1986. The Gods of the Celts. Gloucester: Sutton.

Green, Miranda Jane 1992. Dictionary of Celtic Myth and Legend. London: Thames \& Hudson.

Green, Miranda Jane 1995. Celtic Godesses: warriors, virgins and mothers. London: British Museum Press. 


\section{Daíthí Ó hÓgáin}

Gruffydd, William John (tõlk) 1928. Math Wab Mathonwy: An inquiry into the origins and development of the 4th branch of the Mabinogi. Cardiff: University Wales Press.

Guénon, René 1962. Symboles Fondamentaux de la Science Sacrée. Paris: Gallimard.

Gwynn, Edward John 1906. The metrical Dindshenchas: Text, translation, and commentary 2. Dublin: Academy House.

Gwynn, Edward John 1924. The metrical Dindshenchas: Text, translation, and commentary 4. Dublin: Academy House.

Gwynn, Edward John (toim) 1940/42. An Old-Irish Tract on Privileges and Responsibilities of Poets. Ériu 13, 1940/42, lk 1-60, 220-236.

Hamel, Anton Gerardus van (toim) 1932. Lebor Bretnach: The Irish version of the Historia Britonum ascribed to Nennius. Baile Átha Cliath (Dublin): Oifig an tSolathair.

Hamel, Anton Gerardus van 1941. Immrama. Mediaeval and modern Irish series 10. Dublin: The Stationery Office.

Hesiodos. Theogonia.

Holder, Alfred 1896. Alt-Celtischer Sprachschatz 2. Leipzig:Teubner.

Homeros 1963. Odüsseia. Tallinn: Eesti Riiklik Kirjastus.

Hull, Vernam 1931. De Gabáil in t-Sída. Zeitschrift für celtische Philologie 19, lk 53-58.

Jackson, Kenneth 1953. Language and History in Early Britain: A chronological survey of the Brittonic languages 1st to 12th c. Edinburgh. University Press.

Knott, Eleanor 1936. Togail Bruidne Da Derga. Mediaeval and modern Irish series 8. Dublin: The Stationery Office.

Krappe, Alexander Haggerty 1927. Balor with the Evil Eye. New York: Institut des Études Françaises of Columbia University.

Lysaght, Patricia 1986. The Banshee: The Irish supernatural death-messenger. Dublin: O’Brien Press.

Mac Cana, Proinsias 1980. The Learned Tales of Medieval Ireland. Dublin: Dublin Institute for Advanced Studies.

Macalister, Robert Alexander Stewart (tõlk ja toim) 1938-1956. Leabhar gabhála = Lebor gabála Érenn: The book of the taking of Ireland 5. Irish Texts Society Publications. Dublin: Published for the Irish Texts Society by the Educational Company of Ireland.

Mallory, James P. \& Adams, Douglas Q. 1997. Encyclopedia of Indo-European Culture. London: Fitzroy Dearborn. 


\section{Daíthí Ó hÓgáin}

Meyer, Kuno \& Nutt Alfred 1895. The Voyage of Bran, son of Febal, to the land of the living: An old Irish saga. Grimm Library 4. London: Nutt.

Meyer, Kuno 1919. Der irische Totengott und Toteninsel. Gesamtsitzung vom 26 Juni. Mitteilung aus der Sitzung der phil.-hist. Klasse vom 19 Juni. Sitzungsberichte der Königlich Preussischen Akademie der Wissenschaften 32. Königliche Akademie der Wissenschaften.

Mohen, Jean-Pierre 1990. The World of Megaliths. New York \& Oxford: Facts on File.

Murphy, Gerald 1953/55. Notes on Cath Maige Tuired. Éigse: A journal of Irish studies 7. Dublin: National University of Ireland, lk 191-198.

Müller-Lisowski, Käte 1948. Béaloideas: Iris an Chumainn le Béaloideas Éireann = The Journal of the Folklore of Ireland Society 18.

Ní Shéaghdha, Nessa 1967. Tóruigheacht Dhiarmada agus Ghráinne = The pursuit of Diarmaid and Gráinne. Irish Texts Society Publications = Irish Texts Society Series 48. Dublin: Published for the Irish Texts Society by the Educational Company of Ireland.

O’Brien, Michael A. 1962. Corpus Genealogiarum Hiberniae. Dublin: Dublin Institute for Advanced Studies.

Ó Buachalla, Breandán 1996. Aisling Ghéar: Na Stiobhartaigh agus an taos leinn. Baile Átha Cliath (Dublin): An Clochomhar.

Ó Catháin, Séamas 1995. The Festival of Brigit: Celtic goddess and holy woman. Blackrock \& Dublin: DBA Publications.

Ó Danachair, Caoimhín (= Danaher, Kevin) 1972. The Year in Ireland. Cork: Mercier Press.

Ó hÓgáin, Dáithí 1982. An File: Staidear ar osnadurthacht na filiochta sa traidisiun gaelach. Baile Átha Cliath (Dublin): Oifig An tSolathair.

Ó hÓgáin, Dáithí 1990. Myth, Legend and Romance: An encyclopaedia of the Irish folk tradition. London: Ryan Publishing.

Ó hÓgáin, Dáithí 1992/93. Migratory Legends in Mediaeval Irish Literature. Béaloideas: Iris an Chumainn le Béaloideas Éireann = The Journal of the Folklore of Ireland Society 60/61, lk 57-74.

Ó hÓgáin, Dáithí 1995. Irish Superstitions. Dublin: Gill \& Macmillan.

Ó hÓgáin, Dáithí 1999. The Sacred Isle: Belief and religion in pre-Christian Ireland. Cork: Collins Press.

O'Meara, John Joseph (tõlk) 1978. The Voyage of Saint Brendan = Navigatio Sancti Brendani Abbatis. Dublin: Dolmen Press.

O’Rahilly, Cecile 1976. Táin Bó Cuailnge: Recension 1. Dublin: Dublin Institute for Advanced Studies. 
O'Rahilly, Thomas Francis 1946. Early Irish History and Mythology. Dublin: Dublin Institute for Advanced Studies.

O'Rourke, Brian 1984-1985. The Long Walk of a Queen: The Representation of Ireland as a woman in the Irish literary tradition. Chiba Review 6, lk 1-73; 7, lk 1-49.

Pettazzoni, Rafaele 1956. The All-Knowing God: Researches into early religion and culture. London: Methuen \& Co.

Rank, Otto 1914. The Myth of the Birth of the Hero: A psychological interpretation of mythology. New York: The Journal of nervous and mental disease publishing company.

Rees, Alwyn \& Rees, Brinley 1973. Celtic Heritage: Ancient tradition in Ireland and Wales. London: Thames and Hudson.

Roider, Ulrike (tõlk) 1979. De Chophur in Da Muccida = Wie die beiden Schweinehirten den Kreislauf der Existenzen durchwanderten: Eine altirische Sage. Innsbruck: Institut für Sprachwissenschaft der Universität Innsbruck.

Rose, Herbert Jennings 1957. Gods and Heroes of the Greeks: An introduction to Greek mythology. London: Methuen \& Co.

Saintyves, Pierre 1928. Le Massacres des Innocents ou la Persécution de l'Enfant predestine. Paul Louis Couchoud (koost). Jubilé' Alfred Loisy: Congrés d'Histoire du Christianisme 3. Paris: Rieder \& Amsterdam: Van Holkema.

Schusky, Ernest Lester \& Culbert, T. Patrick 1973. Introducing Culture. Prentice-Hall anthropology series. Englewood Cliffs: Prentice-Hall.

Todd, James Henthorn 1848. Irish version of the Historia Britonum of Nennius. Dublin: Printed for the Irish archaeological society.

Walde, Alois \& Pokorny, Julius 1930. Vergleichendes Wörterbuch der Indogermanischen Sprachen 1. Berlin: de Gruyter.

Williams, Ifor 1930. Mabinogio: Pedeir Keinc y Mabinogi. Caerdydd (Cardiff): Gwasg Prifysgol Cymru.

Vries, Jan de 1961. Keltische Religion. Die Religionen der Menschheit 18. Stuttgart: Kohlhammer. 